\title{
PREDICTING LONG-TERM FUNCTIONAL RESULTS AFTER MYOCARDIAL REVASCULARIZATION IN ISCHEMIC CARDIOMYOPATHY
}

Giovanni Battista Luciani, MD

Giuseppe Montalbano, MD

Gianluca Casali, MD

Alessandro Mazzucco, MD
Objective: The goal of the present study was to define the early and late functional results after revascularization in ischemic cardiomyopathy and to identify variables predictive of a favorable outcome.

Methods: A retrospective review of all consecutive patients with ischemic cardiomyopathy undergoing myocardial revascularization between January 1991 and June 1998 was undertaken. One hundred sixty-seven patients (140 men) aged $60 \pm 8$ years (range, 39-77 years) with angina $(n=107)$, congestive heart failure $(n=54)$, or silent ischemia $(n=6)$ were identified. One hundred six $(63 \%)$ patients with angina were in Canadian Cardiovascular Society class III or IV, and $40(24 \%)$ patients with congestive failure were in New York Heart Association class III or IV. The preoperative left ventricular ejection fraction averaged $0.28 \pm 0.05$ (range, $0.16-0.30$ ). Thirteen $(8 \%)$ patients required preoperative mechanical life support. A mean of $2.9 \pm 0.9$ grafts per patient were performed, with an average myocardial ischemia time of $53 \pm 23$ minutes and bypass time of $104 \pm 31$ minutes.

Results: There were $3(1.7 \%)$ early deaths and 21 (13\%) deaths during follow-up (2.7 \pm 2.1 years; range, 0.3-7.8 years), producing a survival of $94 \%$ $\pm 2 \%$ and $75 \% \pm 10 \%$ at 1 and 5 years, respectively. Despite a significant increase in left ventricular ejection fraction $(0.28 \pm 0.05$ vs $0.38 \pm 0.09, P=$ $.0001)$, only $89(54 \%)$ patients were symptom-free at follow-up. Freedom from recurrent angina was $98 \% \pm 1 \%$ and $81 \% \pm 8 \%$, whereas freedom from congestive failure was $78 \% \pm 11 \%$ and $47 \% \pm 20 \%$ at 1 and 5 years, respectively. Follow-up New York Heart Association class in patients with congestive failure was improved (40/54 class III-IV vs $11 / 54$ class III-IV, $P=$ $.0001)$. Multivariate analysis showed a lower ejection fraction $(P=.01)$, preoperative congestive failure $(P=.03)$, and a need for preoperative intra-aortic balloon pumping $(P=.03)$ to be associated with a greater prevalence of recurrent congestive failure, whereas male sex $(P=.01)$, preoperative angina $(P=.04)$, use of the internal thoracic artery $(P=.03)$, and higher number of grafts $(P=.01)$ were associated with lower prevalence. Male sex $(P=.06)$, higher number of grafts $(P=.04)$, and shorter duration of myocardial ischemia $(P=.04)$ were also predictive of improvement in New York Heart Association class at follow-up.

Conclusions: Despite satisfactory early and late survival, late functional outcome after myocardial revascularization in ischemic cardiomyopathy remains suboptimal because of recurrence or persistence of congestive failure. Selection of appropriate surgical candidates and extensive use of complete revascularization with the internal thoracic artery may substantially improve functional results. (J Thorac Cardiovasc Surg 2000;120:478-89)
From the Division of Cardiac Surgery, University of Verona, Verona, Italy.

Presented in part at the Seventy-second Meeting of the American Heart Association, Atlanta, Ga, 1999.

Received for publication Feb 4, 2000; revisions requested April 11, 2000; revisions received April 27, 2000; accepted for publication May 17, 2000.
Address for reprints: Giovanni Battista Luciani, MD, Division of Cardiac Surgery, University of Verona, O. C. M. Piazzale Stefani 1, Verona, 37126, Italy (E-mail: luciani@netbusiness.it).

Copyright (c) 2000 by The American Association for Thoracic Surgery

$0022-5223 / 2000 \$ 12.00+0 \quad \mathbf{1 2} / \mathbf{1} / \mathbf{1 0 8 6 9 2}$

doi:10.1067/mtc. 2000.108692 
$T^{\text {he }}$ he rapid extension of heart transplantation to a wider category of patients with end-stage heart disease in the late 1980s has been responsible for the increasing discrepancy between the demand for heart transplantation and offers of viable donor organs. ${ }^{1}$ The realization that high-risk surgical options could be offered to selected patients initially evaluated as potential transplant recipients led several pilot institutions to redefine the relative indications for heart transplantation. ${ }^{2-6}$ It was readily apparent that a proportion of patients with end-stage ischemic heart disease could be offered myocardial revascularization at the expense of greater operative risk but with an overall early outcome absolutely comparable with that of heart transplantation. ${ }^{2,6}$ The awareness that selection criteria were needed to identify patients who would benefit from revascularization ${ }^{5}$ promoted the widespread use of laboratory investigation to identify areas of viable myocardium, albeit in a quiescent or hibernated state. ${ }^{7-9}$ Progress in the field of imaging and metabolic diagnostic techniques, as well as advancements in the strategies of intraoperative myocardial protection and postoperative care, must be credited for the significant decrease in operative risk for patients with ischemic cardiomyopathy undergoing coronary artery bypass surgery observed in the early 1990s. ${ }^{10-13}$ Medical management of congestive heart failure likewise witnessed substantial improvements with the introduction of angiotensinconverting enzyme inhibitors in clinical practice. ${ }^{14}$ With the availability of a series of valid medical and surgical therapeutic options for ischemic cardiomyopathy, it has become necessary to identify more stringent selection criteria for revascularization. In particular, negligible attention has thus far been devoted to the assessment of late functional outcome of patients after coronary bypass surgery, which must also be taken into consideration when a treatment option is chosen. The purpose of the present study was to define the longterm functional results after myocardial revascularization for ischemic cardiomyopathy and to identify factors predictive of favorable outcome.

\section{Methods}

Patient selection. Between January 1991 and June 1998, 5579 consecutive patients with ischemic heart disease underwent myocardial revascularization (coronary artery bypass grafting) at our institution. One hundred sixty-seven (2.9\%) had severe left ventricular failure (left ventricular ejection fraction $[\mathrm{LVEF}]<30 \%$ ) and were thus retrospectively selected for the study. Inclusion criteria throughout the observation period were clinical (ie, angina) evidence, laboratory (ie, positive stress test result) evidence, or both, of ischemic heart disease with angiographic demonstration of critical obstruc- tive coronary artery lesions. Estimates of LVEF were gathered from biplanar left ventricular angiograms in all patients. Exclusion criteria were the presence of a recent (ie, $<1$ month old) myocardial infarction, the existence of valve disease, or the existence of a left ventricular aneurysm necessitating surgical treatment. Myocardial viability studies to further identify suitable surgical candidates were gradually adopted during the observation period and became routine at our institution only in 1994. Accordingly, stress and rest-redistribution 201 thallium scintiscan, low-dose dobutamine echocardiography, or both, were used to image areas of viable (ie, hibernated) myocardium. Because of cost considerations, positron emission tomography was used only in cases of inconclusive response with the aforementioned laboratory investigations or when both results were negative despite the presence of angina, as reported in the management algorithm depicted in Fig 1. The demographic variables of the patient population are summarized in Table I.

Operative technique. All procedures were performed through a median sternotomy with the aid of moderately hypothermic $\left(28^{\circ} \mathrm{C}\right)$ cardiopulmonary bypass by using aortic and right atrial cannulation and left ventricular venting through the right superior pulmonary vein. Complete myocardial revascularization with venous and arterial conduits was the goal in every patient. Use of the left internal thoracic artery on the left anterior descending branch was routinely extended to all patients 70 years old or younger. In older patients the left internal thoracic artery was used on an individual basis. All distal coronary anastomoses were performed first. The proximal anastomoses were performed with total aortic crossclamping or partial occlusion at the surgeon's discretion. Before 1995, myocardial preservation was obtained by intermittent injection of cold $\left(4^{\circ} \mathrm{C}\right)$ crystalloid cardioplegic solution through the antegrade route. After aortic crossclamping, $1000 \mathrm{~mL}$ of St Thomas' Hospital II solution was injected into the aortic root at a rate of 150 to 300 $\mathrm{mL} / \mathrm{min}$. The dose was continued in case of persistent electrical activity to achieve cardiac standstill. Topical cooling of the heart with ice-slush was also used. Maintenance doses $(500 \mathrm{~mL})$ of cardioplegic solution were administered every 30 minutes. After 1995, cold blood induction and maintenance and warm reperfusion cardioplegia through the antegrade and retrograde (ie, coronary sinus) routes was used according to Buckberg's principles..$^{15} \mathrm{~A}$ cold $\left(4^{\circ} \mathrm{C}\right)$ induction dose of $10 \mathrm{~mL} / \mathrm{kg}$ was administered at 150 to $300 \mathrm{~mL} / \mathrm{kg}$ through the antegrade (two thirds of dose) and retrograde (one third of dose) routes. The dose was continued until cardiac standstill in case of persistent electrical activity. Maintenance cold doses of $5 \mathrm{~mL} / \mathrm{kg}$ were administered through the coronary sinus every 20 minutes. Warm $\left(30^{\circ} \mathrm{C}\right.$ $32^{\circ} \mathrm{C}$ ) reperfusion was administered alternatively through the antegrade or retrograde route at 150 to $300 \mathrm{~mL} / \mathrm{min}$ for 3 minutes before aortic clamp release. The operative variables of the patient population are reported in Table II.

Follow-up. Perioperative information was obtained from hospital records. Cross-sectional follow-up was conducted between August and September 1998 by telephone interview 


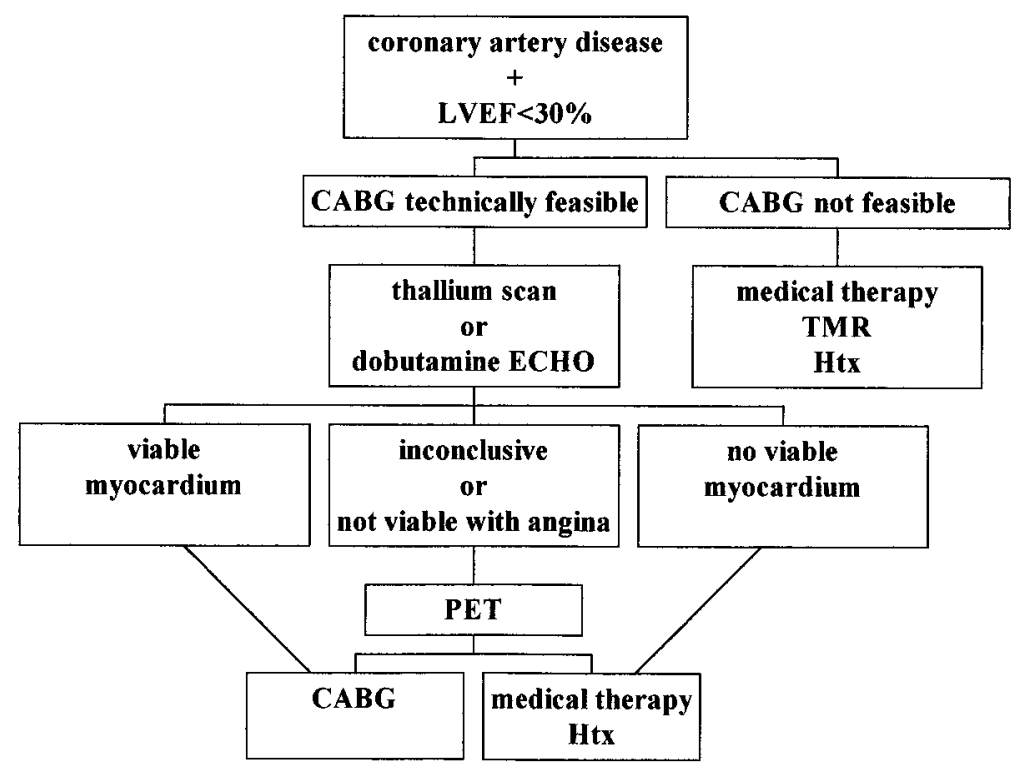

Fig 1. Management algorithm for patients with ischemic cardiomyopathy. A thallium scan is defined as stress thallium-201 single-photon emission computed tomography with reinjection at rest before redistribution, and dobutamine echocardiography $(E C H O)$ is defined as low-dose $(5-10 \mu \mathrm{g})$ and high-dose $(10-20 \mu \mathrm{g})$ dobutamine stress echocardiography. $C A B G$, Coronary artery bypass grafting; $T M R$, transmyocardial laser revascularization; $H t x$, heart transplantation; PET, fluoro-18-deoxyglucose positron emission tomography.

Table I. Demographic data

\begin{tabular}{|c|c|c|}
\hline No. of patients & 167 & \\
\hline $\operatorname{Sex}(M / F)$ & $140 / 27$ & \\
\hline Age (y) & $60 \pm 8$ & $(39-77)^{*}$ \\
\hline Hypertension & $65 \quad(38.9 \%)$ & \\
\hline Diabetes mellitus & $40 \quad(24.0 \%)$ & \\
\hline Hyperlipidemia & $65 \quad(38.9 \%)$ & \\
\hline Prior MI & $157 \quad(94.0 \%)$ & \\
\hline Episodes of MI per patient & $1.2 \pm 0.4$ & $(1-3)^{*}$ \\
\hline Angina & $146 \quad(87.4 \%)$ & \\
\hline Congestive heart failure & $54 \quad(32.3 \%)$ & \\
\hline Silent ischemia & $6 \quad(3.6 \%)$ & \\
\hline Ventricular arrhythmias & $(4.7 \%)$ & \\
\hline Class III-IV CCS & $106 \quad(63.5 \%)$ & \\
\hline Class III-IV NYHA & $40 \quad(24.0 \%)$ & \\
\hline Three-vessel disease & $114 \quad(68.3 \%)$ & \\
\hline LVEF & $0.28 \pm 0.05$ & $(0.16-0.30)^{*}$ \\
\hline Myocardial viability study & $81 \quad(48.5 \%)$ & \\
\hline
\end{tabular}

MI, Myocardial infarction; CCS, Canadian Cardiovascular Society; NYHA, New York Heart Association.

*Range is given in parentheses.

or direct assessment at follow-up physical and laboratory examination. Patient follow-up was $100 \%$ complete.

Statistical analysis. Data were reported as mean values \pm $\mathrm{SD}$ or as proportions. Comparison of continuous variables was done by a 2 -tailed Student $t$ test for paired data. The Pearson $\chi^{2}$ or Fisher exact tests were used for categoric variables as appropriate. Survival curves were constructed by the
Kaplan-Meier method. Differences in survival were determined by the log-rank test. Multivariate correlates of survival were identified by the Cox proportional hazard method. Multivariate correlates of hospital death, recurrent angina, recurrent congestive failure, and improvement of Canadian Cardiovascular Society (CCS) and New York Heart Association (NYHA) class at follow-up were determined by stepwise logistic regression analysis. The list of variables entered in the analysis is as follows: age, sex, angina, congestive heart failure, silent ischemia, ventricular arrhythmia, hypertension, hyperlipidemia, diabetes, prior myocardial infarction, CCS functional class, NYHA functional class, laboratory evidence of viable myocardium, LVEF, prior cardiac operation, preoperative intra-aortic balloon pumping (IABP), year of operation, urgent operation, number of grafts, use of the left internal thoracic artery, duration of myocardial ischemia, duration of cardiopulmonary bypass, and use of blood cardioplegia.

The primary end points of the study were as follows: early mortality (before hospital discharge or within 30 days of operation), late mortality, cardiac-related mortality (myocardial infarction, congestive heart failure, arrhythmia, or sudden death), recurrence of angina, recurrence of heart failure, and functional outcome. Functional outcome was evaluated by comparison of preoperative and 6-month follow-up echocardiographic measurements of LVEF, preoperative and follow-up clinical status according to the NYHA for congestive heart failure and CCS for angina, and evaluation of qual- 


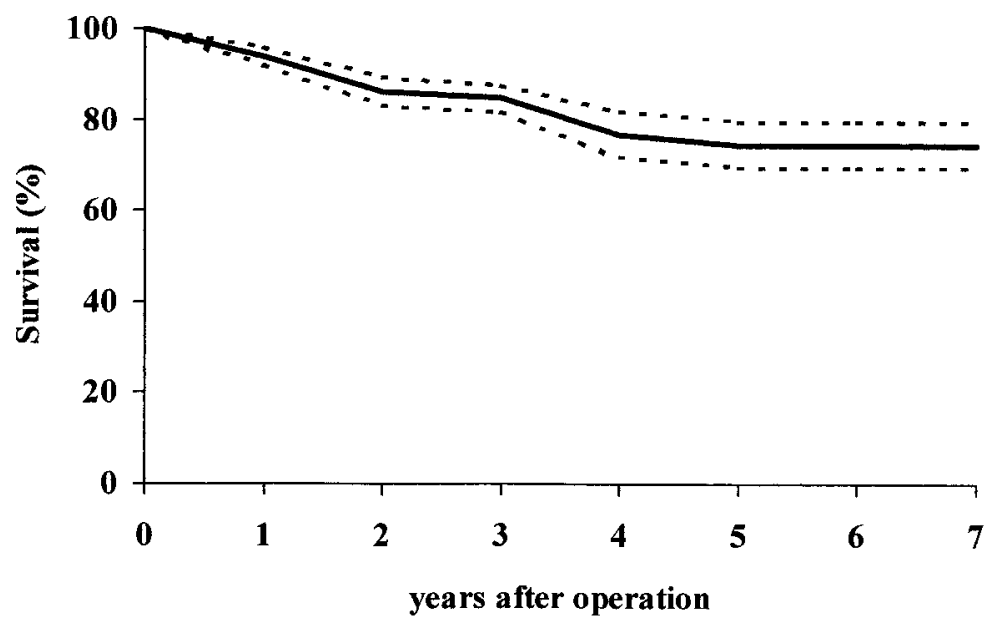

Fig 2. Overall survival of 167 patients with ischemic cardiomyopathy undergoing myocardial revascularization at the University of Verona between January 1991 and June 1998. Dashed lines represent 70\% confidence limits.

Table II. Operative data

\begin{tabular}{lcrc}
\hline Prior CABG & 9 & $(5.3 \%)$ & \\
Urgent operation & 24 & $(14.4 \%)$ & \\
Preoperative IABP support & 13 & $(7.7 \%)$ & \\
Grafts per patient & $2.9 \pm 0.9$ & & $(1-5)^{*}$ \\
LITA graft & 104 & $(62.3 \%)$ & \\
Aortic crossclamp (min) & $53 \pm 23$ & & $(19-95)^{*}$ \\
CPB (min) & $104 \pm 31$ & & $(34-208)^{*}$ \\
Blood cardioplegia & 109 & $(65.3 \%)$ & \\
\hline
\end{tabular}

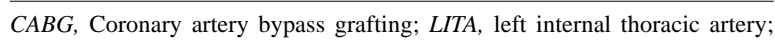
$C P B$, cardiopulmonary bypass.

"Range is given in parentheses.

ity of life. The latter was assessed by means of a simplified self-administered questionnaire, which examined prevalence of active employment and severity of subjective physical limitation (graded as limited activity, partial limitation, or no limitation).

\section{Results}

Early clinical outcome. There were $3(1.7 \%)$ early deaths, all of which were of a cardiac cause. One patient died on the second postoperative day as a result of low cardiac output after perioperative myocardial infarction, despite mechanical life support with a left ventricular assist device. The second casualty was in a patient undergoing the third myocardial revascularization procedure for unstable angina, who manifested irreversible low output syndrome refractory to IABP and high-dose catecholamine support. Perioperative myocardial infarction was ruled out on the basis of lab-
Table III. Correlates of late mortality

\begin{tabular}{lcc}
\hline \multicolumn{1}{c}{ Variable } & $\beta$ Factor & P value \\
\hline Preoperative LVEF & -7.99 & .07 \\
No. of bypass grafts & -0.69 & .03 \\
Duration of CPB & 0.02 & .07 \\
\hline
\end{tabular}

Multivariate analysis with Cox model. $L V E F$, Left ventricular ejection fraction; $C P B$, cardiopulmonary bypass.

oratory and electrocardiographic findings. The third early death occurred in a patient with silent ischemia and a history of ventricular tachyarrhythmia who had an unremarkable recovery in the intensive care unit but experienced ventricular fibrillation on the regular ward. Univariate analysis demonstrated that angina was associated with a decreased risk of hospital mortality $(P=$ .04 ), whereas prolonged duration of cardiopulmonary bypass was associated with an increased risk of the same event $(P=.03)$. When entered into the multivariate analysis, none of the variables examined proved predictive.

Major nonfatal postoperative complications were observed in 40 (24\%) patients. Postoperative myocardial infarction was diagnosed in $9(5 \%)$ patients, 8 of whom required catecholamine and IABP support. Fourteen $(8 \%)$ additional patients showed reversible low cardiac output syndrome in the absence of laboratory and electrocardiographic evidence of perioperative myocardial infarction. Hemodynamic stabilization was achieved by means of IABP support in 3 of these patients, 2 of whom had required preoperative IABP support as well. Life-threatening ventricular arrhyth- 


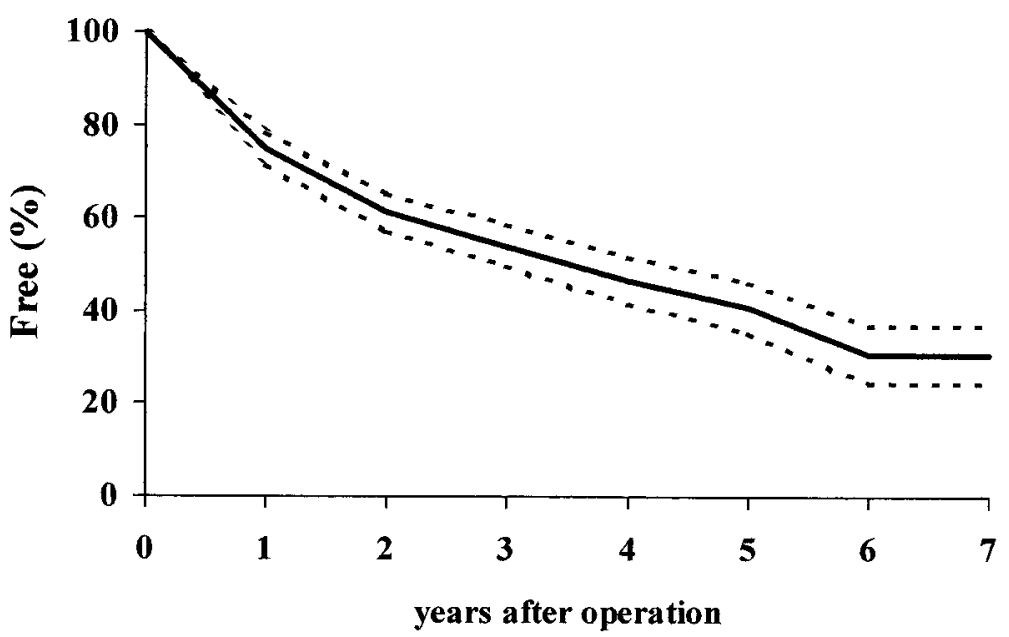

Fig 3. Overall symptom-free survival of 167 patients with ischemic cardiomyopathy undergoing myocardial revascularization at the University of Verona between January 1991 and June 1998. Dashed lines represent 70\% confidence limits.

Table IV. Correlates of late cardiac-related mortality

\begin{tabular}{lcc}
\hline Variable & $\beta$ Factor & $\mathrm{P}$ value \\
\hline Preoperative LVEF & -5.55 & .06 \\
No. of bypass grafts & -0.30 & .06 \\
Duration of CPB & 0.04 & .04
\end{tabular}

Multivariate analysis with Cox model. $L V E F$, Left ventricular ejection fraction; $C P B$, cardiopulmonary bypass.

mias were recorded in $5(3 \%)$ patients, 1 of whom needed resuscitation with open-chest cardiac massage and an IABP, subsequently. Emergency repeat coronary angiography in the latter patient demonstrated patency of all the bypass grafts. Four (2\%) patients required prolonged mechanical ventilatory support for respiratory failure. Two (1\%) patients had a postoperative cerebrovascular accident, and 1 had acute renal failure necessitating dialysis. Postoperative bleeding leading to re-exploration occurred in 3 (2\%) patients.

Late clinical outcome. Twenty-one late casualties were recorded during a follow-up period ranging from 0.3 to 7.8 years (mean, $2.7 \pm 2.1$ years). Actuarial survival was $94 \% \pm 2 \%, 75 \% \pm 8 \%$, and $75 \% \pm 8 \%$ at 1 , 5 , and 7 years, respectively (Fig 2). Cause of late mortality was cardiac in 15 patients (progressive heart failure in 7, sudden death in 5, and myocardial infarction in 3), giving an actuarial freedom from cardiac death of $95 \% \pm 1 \%, 84 \% \pm 5 \%$, and $84 \% \pm 5 \%$ at 1,5 , and 7 years, respectively. Noncardiac cause of death included malignancy in 5 patients and stroke in 1 patient. Multivariate analysis showed the number of bypass grafts and ejection fraction to be inversely correlated with late mortality, whereas duration of cardiopulmonary bypass was directly correlated with it (Table III). The significance of the following findings increased when late cardiac mortality was used as an end point (Table IV).

Late complications, excluding those of cardiac origin that are reported below, were cerebrovascular accident in 2 patients and right leg amputation in a patient with severe peripheral vascular disease.

Late functional outcome. Laboratory evidence of successful functional outcome of myocardial revascularization was suggested by a significant improvement in ejection fraction at 6-month follow-up echocardiography $(0.28 \pm 0.05$ vs $0.38 \pm 0.09, P=.001)$. However, no correlates predictive of increase in ejection fraction could be isolated, possibly because of the wide distribution of follow-up values.

Eighty-nine (54\%) of 164 operative survivors were symptom-free at follow-up assessment. Actuarial symptom-free survival for the entire patient population was $75 \% \pm 8 \%, 41 \% \pm 16 \%$, and $31 \% \pm 18 \%$ at 1,5 , and 7 years, respectively (Fig 3).

Recurrent angina was diagnosed in 17 (10\%) operative survivors, 7 of whom had associated congestive failure. Fourteen of these patients had presented with angina at operation, whereas 3 had been referred for angina combined with congestive heart failure (Fig 4). Four of 10 patients with angina alone at follow-up had elective repeat coronary angiography, which showed patency of all 3 bypass grafts in 1 patient, of 2 of 3 grafts in 1 patient, of 1 of 3 grafts in 1 patient, and 


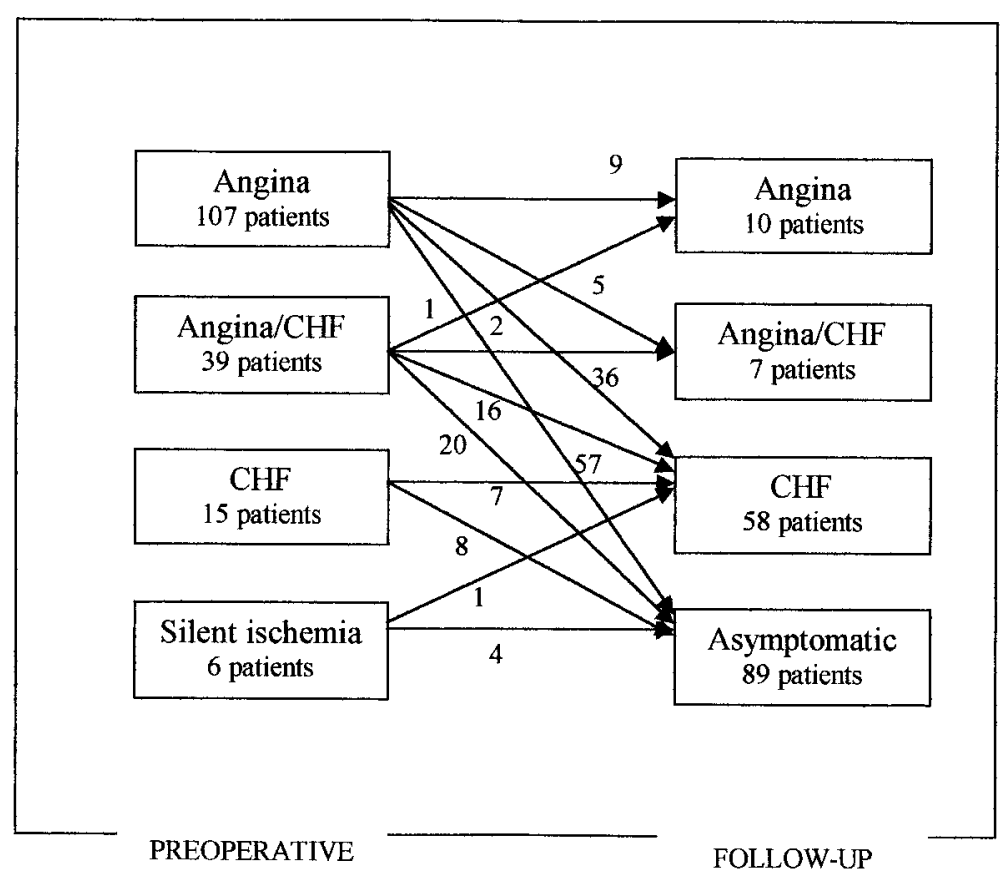

Fig 4. Diagram depicting the evolution of the clinical picture of 167 patients with ischemic cardiomyopathy undergoing myocardial revascularization at the University of Verona between January 1991 and June 1998. Note that the total number of patients at follow-up is 164 , corresponding to the operative survivors. $C H F$, Congestive heart failure.

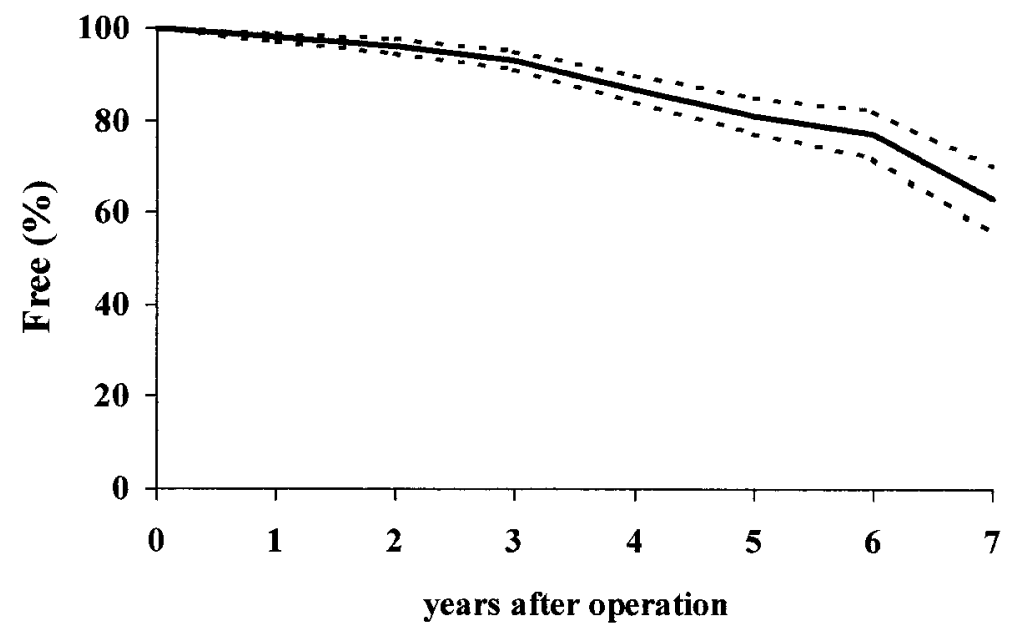

Fig 5. Overall angina-free survival of 167 patients with ischemic cardiomyopathy undergoing myocardial revascularization at the University of Verona between January 1991 and June 1998. Dashed lines represent 70\% confidence limits.

occlusion of all grafts in the last patient. Two of the 4 patients undergoing repeat invasive evaluation received a percutaneous transluminal coronary angioplasty during the procedure, whereas the remaining patients with recurrent angina or mixed symptoms were assigned to medical treatment and showed either clinical improvement or stabilization. Actuarial freedom from recurrent angina was $98 \% \pm 1 \%, 81 \% \pm 8 \%$, and $63 \% \pm 10 \%$ at 1,5 , and 7 years, respectively (Fig 5). No correlates of recurrent angina could be disclosed. 


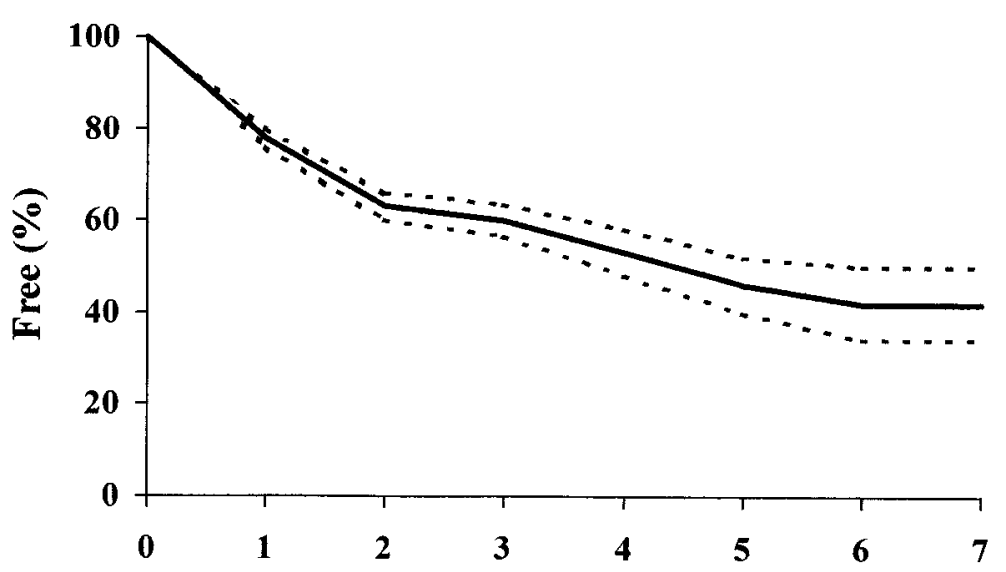

Fig 6. Overall congestive heart failure-free survival of 167 patients with ischemic cardiomyopathy undergoing myocardial revascularization at the University of Verona between January 1991 and June 1998. Dashed lines represent $70 \%$ confidence limits.

Table V. Correlates of recurrent $\mathrm{CHF}$

\begin{tabular}{lcc}
\hline Variable & Odds ratio & P value \\
\hline Male sex & 0.28 & .01 \\
LVEF & 0.48 & .01 \\
CHF & 1.40 & .03 \\
Angina & 0.93 & .04 \\
Preoperative IABP & 3.34 & .03 \\
Use of LITA & 0.84 & .03 \\
No. of bypass grafts & 0.99 & .01
\end{tabular}

$\overline{\text { Multivariate analysis with regression model. } L V E F \text {, Left ventricular ejection }}$ fraction; $C H F$, congestive heart failure; $I A B P$, intra-aortic balloon pumping; LITA, left internal thoracic artery.

Congestive heart failure was observed in 65 (40\%) operative survivors at follow-up, 7 of whom manifested recurrent angina, as specified above. Thus actuarial freedom from recurrent congestive failure was $78 \% \pm$ $10 \%, 47 \% \pm 20 \%$, and $42 \% \pm 22 \%$ at 1,5 , and 7 years, respectively (Fig 6). Although all patients with recurrent angina had the same as a presenting symptom, this did not apply to patients showing recurrent, persistent, or newly diagnosed heart failure. The variability of the evolution of clinical status as related to the type of symptom at follow-up is depicted in Fig 4. Three patients with rapidly progressing congestive failure and absence of viable myocardium at follow-up evaluation were listed for heart transplantation. The remaining were maintained on medical therapy alone. Several variables were identified as correlates of recurrent heart failure. In particular, lower LVEF, presentation with congestive failure, and need for preoperative IABP
Table VI. Correlates of NYHA class variation

\begin{tabular}{lcc}
\hline Variable & $\beta$ Factor & P value \\
\hline Angina & -0.12 & .02 \\
Male sex & -0.14 & .06 \\
Aortic crossclamp & 0.19 & .04 \\
No. of bypass grafts & -0.18 & .04 \\
\hline
\end{tabular}

Multivariate analysis with Cox model. NYHA, New York Heart Association.

were associated with a greater likelihood, whereas male sex, preoperative angina, use of a left internal thoracic graft, and greater number of bypass grafts were associated with a lesser likelihood of congestive heart failure at follow-up (Table V). Average CCS functional class for the entire population improved from $2.8 \pm 0.9$ to $1.7 \pm 0.5$ at follow-up $(P=.01)$, whereas improvement in average NYHA functional class was not evident ( $1.6 \pm 0.9$ vs $1.7 \pm 0.8$, not significant), possibly because of the high prevalence of congestive heart failure at follow-up evaluation. When only patients presenting with heart failure were examined, however, a significant improvement in NYHA class was disclosed, as attested to by the shift of patients toward lower functional classes (40/54 patients preoperatively vs $11 / 54$ patients postoperatively in NYHA class III-IV, $P=.001)$. Multivariate correlates of improvement in CCS functional class could not be identified. On the contrary, male sex, presentation with angina, and higher number of bypass grafts had a positive predictive effect of improvement in NYHA class, whereas longer duration of myocardial ischemia had a negative predictive effect (Table VI). 
A simplified, self-administered quality-of-life questionnaire was administered to all 143 long-term survivors (median age at follow-up of 65 years; range, 4679 years), and 123 (90\%) of them responded. Twenty-two patients had returned to active employment, representing $18 \%$ of the overall population and $36 \%$ of the patients below retirement age. Thirty-seven (29\%) patients felt physically limited in their daily activity, $21(16 \%)$ felt only partially limited, and 70 $(55 \%)$ felt no limitation at all.

\section{Discussion}

Survival. Myocardial revascularization has evolved into a safe treatment modality for selected patients with ischemic cardiomyopathy. The present work demonstrates that coronary artery bypass grafting can nowadays be offered to patients with ischemic left ventricular failure at a low operative risk (as low as $2 \%$ ) and with a satisfactory long-term outlook.

Comparison of survival estimates after myocardial revascularization with previously published series presents some shortcomings. In particular, patient selection criteria are not uniform among the various clinical reports, as regards the upper-end limit of LVEF and the inclusion of patients with acute myocardial infarction, left ventricular aneurysm, or valve disease necessitating surgical treatment. ${ }^{16}$ The clinical results further differ whether referred to comprehensive series of consecutive patients ${ }^{10,13,17}$ or to limited cohorts of patients selected on the basis of detection of viable myocardium. ${ }^{11,12}$ These limitations notwithstanding, an operative mortality ranging from $2 \%$ to $10 \%$ has recently been reported for large (ie, 100 or more consecutive patients) clinical series by Kaul, ${ }^{10}$ Trachiotis, ${ }^{13}$ Christakis, ${ }^{17}$ and Langenburg, ${ }^{18}$ and their colleagues. Detailed analysis of the present experience shows that aside from a very low operative mortality, in line with the estimates quoted above, surgical revascularization still imposes substantial cardiac morbidity to patients with ischemic cardiomyopathy (myocardial infarction, 5\%; low output syndrome, $8 \%$; IABP use, $13 \%)$. This observation is entirely consistent with the findings of Christakis and associates ${ }^{17}$ (myocardial infarction, $11 \%$; low output, 31\%; IABP use, 16\%) and partly with those of Trachiotis and associates ${ }^{13}$ (myocardial infarction, $1 \%$; IABP use, $11 \%$ ). Long-term outcome after myocardial revascularization is also satisfactory in the present study and in agreement with previously reported actuarial 5-year survivals between 64\% and $73 \% .^{10,13}$ Progress in perioperative management of patients with end-stage ischemic heart disease ${ }^{19}$ has been instrumental in turning bypass grafting from a high-risk neglected alternative to transplantation ${ }^{3-6}$ into a low-risk routine treatment modality. However, an even more important role has been played by the constant evolution throughout the last decade of time of patient selection criteria by means of prospective laboratory investigation and of retrospective risk stratification. ${ }^{10-13,17,20,21}$

Accordingly, reviews of large clinical series, such as the current one, have been carried out to isolate preoperative or intraoperative variables, which may predict the outcome of revascularization. Analysis of previous work shows that a series of patient characteristics may be associated with increased operative risk, including advanced age, female sex, lower ejection fraction, comorbid conditions, urgency of operation, and reoperation. ${ }^{10,13,17,20}$ Unfortunately, identification of factors predictive of early mortality proved unrewarding in the present experience, likely because of the very low number of events. On the contrary, both late overall and late cardiac mortality were associated with lower ejection fraction, lower number of bypass grafts, and longer duration of cardiopulmonary bypass. The relation between preoperative ejection fraction and long-term survival is intuitive because it may describe the severity of ischemic left ventricular failure. A similar correlation was also disclosed by Trachiotis and associates, ${ }^{13}$ but not by Kaul and coworkers, ${ }^{10}$ possibly because their study was limited to patients with ejection fractions below $20 \%$. The number of bypass grafts in the current series expresses the completeness of revascularization because two thirds of patients had 3vessel disease. Thus, the finding of an inverse relation between the number of grafts and late mortality once again matches the results of Trachiotis and colleagues, ${ }^{13}$ who found complete myocardial revascularization to be inversely correlated with late death. Both studies extend to ischemic cardiomyopathy, the principle that ability to completely revascularize the myocardium is of great prognostic significance for survival, as shown for coronary operations in general. ${ }^{22}$ Understanding of the role of duration of cardiopulmonary bypass, an operative variable indicative of more complex or complicated procedures, in predicting late survival is less immediate. This factor may also express the severity and extension of ischemic heart disease, whereby longer circulatory assistance may be required to wean a failing heart from bypass.

Functional outcome. Although most of the research efforts have focused on the demonstration that early and late survival after myocardial revascularization is indeed satisfactory, few studies have concentrated on the functional outcome after operation. The demonstration of a short-term improvement in LVEF has generally been regarded as an index of successful functional 
result. ${ }^{5,6,8,9,11,23}$ Contrary to this assumption, more recent evidence has clearly shown that increase in left ventricular systolic performance is not necessarily accompanied by clinical improvement, as it can be measured by NYHA classification, exercise capacity, or quality-of-life scores. ${ }^{12,24-27}$ These findings are of great relevance because medical management of congestive heart failure has also witnessed significant progress in terms of both survival and control of symptoms. ${ }^{14}$ Thus, the choice of the optimal treatment modality in the individual patient with ischemic cardiomyopathy has nowadays become more difficult. Simply looking for a survival benefit may be insufficient to discriminate among therapeutic alternatives.

The present experience shows that recurrence of symptoms late after operation remains a definite problem, despite successful functional outcome, as traditionally evaluated by an increase in LVEF (from $28 \%$ to $38 \%$ ). In general, a 5-year symptom-free survival of $41 \%$ can hardly be considered satisfactory. Closer scrutiny of late functional outcome reveals that revascularization in ischemic cardiomyopathy offers durable relief from angina because more than $80 \%$ of patients are likely to be free from angina 5 years after operation. These results favorably compare with the raw estimates quoted by Trachiotis and colleagues ${ }^{13}(40 \%$ prevalence of return of angina at 5.8 years' mean follow-up) and by Kaul and colleagues ${ }^{10}$ (35\% prevalence at 3.6 years), albeit at a shorter average period of observation (10\% prevalence at 2.7 years in the current series). Although generally found in patients who had angina as a presenting symptom, no variable proved predictive of recurrence in the present experience, once again because of the low number of events recorded during follow-up. Thus, it remains purely speculative whether this discrepancy in outcome, as well as the ability to adequately control recurrent angina simply by augmentation of medical therapy and interventional procedures, may be related to the more extensive use $(62 \%$ of patients vs $20 \%-35 \%$ in the previous series ${ }^{10,13}$ ) of the left internal thoracic artery as the conduit of choice for the left anterior descending artery, as demonstrated in the common coronary surgery population. ${ }^{28}$ Arterial revascularization may also have the potential for saving these critically ill patients from reoperation, which carries a high risk. ${ }^{29}$

As a corollary to the aforementioned observations, congestive heart failure is primarily responsible for the disappointingly high prevalence of persistence or return of symptoms late after operation. This is evident by the extent of overlap between the two respective survival curves (Figs 3 and 6). Estimates of recurrent heart fail- ure are uncommonly reported and vary widely among series of patients with ischemic cardiomyopathy, ranging from $28 \%$ to $63 \%{ }^{12,26,30}$; the present result (ie, $40 \%$ ) is consistent with previous findings. Unlike angina, congestive heart failure may present in any patient subgroup, which is attested to by the fact that half of the symptomatic patients had originally presented with angina and were free from it at follow-up. It is conceivable that de novo appearance of heart failure expresses the relentless evolution toward left ventricular insufficiency, which would not be recognized by short-term echocardiographic assessment as it was carried out in this study and in the majority of previous studies. 5,6,8,11,12,23,25,26 Longitudinal measurement of LVEF is warranted to disclose the relation, if any, between left ventricular systolic function and congestive heart failure late after operation.

Predicting the recurrence or appearance of heart failure has enormous bearing in terms of patient selection, given that late survival after bypass grafting and transplantation is similar, but the quality of life with the latter is affected by the need for long-term medication and the attendant risks of immunosuppression. In the present experience, female sex, history of congestive failure, lower ejection fraction, and need for preoperative IABP support were associated with greater likelihood of heart failure at follow-up. On the contrary, history of angina, use of the left internal thoracic artery, and number of bypass grafts were inversely associated with return of congestive failure. The meaning of clinical variables is rather apparent, even though a relation with recurrent heart failure has never been previously proposed. In fact, female sex has often been associated with adverse late outcome after revascularization in ischemic cardiomyopathy, as have history of congestive failure and lower ejection fraction..$^{10,13}$ The need for preoperative IABP may further identify patients with more severe left ventricular insufficiency. Comparison with existing data is troublesome because few investigators have analyzed return of heart failure in large clinical series. Yamaguchi and colleagues ${ }^{30}$ found diabetes and preoperative left ventricular endsystolic volume index $\left(>100 \mathrm{~mL} / \mathrm{m}^{2}\right)$, but not history of congestive failure, to be predictive of recurrent heart failure in 39 operative survivors followed up for a mean of 3.6 years. The smaller number of patients and the higher proportion with preoperative heart failure (31/41 [76\%] vs 54/167 [32\%]) can account for the discrepancy with the present findings. Whereas the demographic characteristics isolated have an effect on patient selection, the operative variables identified herein have relevant therapeutic implications. Indeed, the unprecedent- 
ed finding that more extensive use of left internal thoracic artery grafts and of complete revascularization may reduce the prevalence of congestive failure late after operation corresponds well to similar conclusions reached by historical studies on the general coronary bypass population. ${ }^{22,31}$ Inability to show a correlation between the type of conduit for revascularization and late cardiac events or control of symptoms by past studies on ischemic cardiomyopathy may have been due to low prevalence of left internal thoracic artery use (ie, between $20 \%$ and $35 \%$ when reported). ${ }^{10,13}$ Common reasons for not using the internal thoracic artery in patients with left ventricular failure during the 1980s were advanced age, urgency of operation, and modest concern for long-term prognosis. ${ }^{17}$ The clinical experience of the past decade has decisively solved these reservations, ${ }^{10,13}$ as confirmed by the present work; therefore, no patient with ischemic cardiomyopathy should be denied a left internal thoracic artery graft. Consensus already exists on the importance of complete myocardial revascularization in decreasing the rate of late adverse events, ${ }^{13}$ although the specific role on recurrence of heart failure has not been established previously.

The substantial prevalence of congestive heart failure at follow-up explains the absence of improvement in mean NYHA functional class of the overall population. It is, however, noteworthy that patients with heart failure had significant attenuation of symptoms, and half of them were asymptomatic at follow-up. This suggests that revascularization may be associated with durable functional improvement, even in patients with pure congestive failure, although less commonly than in patients with a history of angina, as shown by the relation between the latter variable and NYHA class at multivariate analysis. Similar to the results obtained with recurrence of heart failure, male sex and greater number of bypass grafts were predictive of amelioration in functional class. On the basis of the present results, complete myocardial revascularization has the potential for decreasing not only late mortality but also the prevalence and severity of congestive failure. It follows that coronary operations without the use of cardiopulmonary bypass, by definition associated with incomplete revascularization, are not ideally suited for patients with ischemic cardiomyopathy, as recently advocated. ${ }^{32}$

Quality of life was satisfactory in most long-term survivors of coronary bypass grafting, albeit assessed by a rather rudimentary questionnaire limited to mobility status and active employment. Given the profile of the patient population (large number, advanced age, and variable social background), it was believed that compliance to a simplified test would be the greatest. Although no attempt was made at correlating quality of life with preoperative parameters, previous studies with either the Minnesota Living with Heart Failure or the Nottingham Health Profile have failed to disclose any relation with clinical or laboratory data. ${ }^{25,27}$ In particular, it has been shown that identification of viable myocardium ( $\geq 8$ segments at positron emission tomography) may predict improvement in LVEF or exercise capacity but not changes in functional class or quality of life. ${ }^{25,27}$

Finally, considering half of the population of longterm survivors in the present experience was above retirement age at the time of follow-up, an overall active employment rate of $18 \%$ is not necessarily disappointing. In addition, over $70 \%$ of patients felt no or modest physical limitation in routine physical activity, which indicates acceptable functional status despite the high prevalence of persistent or newly presenting heart failure.

Limitations. The current study presents several limitations. It is retrospective and, like most clinical series of surgical revascularization in ischemic cardiomyopathy, not randomized. The bias introduced by changing clinical practice (ie, increasing adoption of blood cardioplegia, myocardial viability tests, and use of the left internal thoracic artery) cannot be easily quantified. Late follow-up echocardiographic and, most important, coronary angiographic examinations were not performed. It is difficult to understand whether unsatisfactory functional outcome is a result of progressing left ventricular insufficiency in turn because of the natural history of bypass grafts or alternatively because of a relentless evolution of the myopathy. This shortcoming afflicts all previously published clinical series. Use of NYHA and CCS classification to measure clinical and functional status has inherent limitations. Different methods, such as the Specific Activity Scale, have instead been proposed, which have greater agreement with exercise treadmill performance. ${ }^{33}$ Nonetheless, NYHA and CCS remain the most commonly adopted scoring systems, and continued use is warranted if clinical series are to be compared.

\section{Conclusions}

The present study demonstrates that operative and late survival after myocardial revascularization in ischemic cardiomyopathy is satisfactory. Whereas durable relief from angina can be expected in the majority of long-term survivors, persistence of congestive heart failure, albeit of lesser severity, or its new appearance represent concerning problems in the late 
follow-up. Patients who present with pure congestive heart failure and lower ejection fractions are at higher risk for late death and return of congestive failure. However, they should not be denied revascularization solely on this basis because evidence for clinical improvement exists. Regardless of the clinical substrate, extension to all patients of complete myocardial revascularization and use of the left internal thoracic artery graft is strongly recommended because it may reduce the mortality and the prevalence and severity of recurrent congestive failure late after the operation.

\section{REFERENCES}

1. Evans RW, Manninen DL, Garrison LP, Maier AM. Donor availability as the primary determinant of the future of heart transplantation. JAMA 1986;255:315-8.

2. Kron IL, Flanagan TL, Blackbourne LH, Schoreder RA, Nolan SP. Coronary revascularization rather than cardiac transplantation for chronic ischemic cardiomyopathy. Ann Surg 1989;210:348-52.

3. Sanchez JA, Smith CR, Drusin RE, Reison DS, Malm JR, Rose EA. High-risk reparative surgery: a neglected alternative to heart transplantation. Circulation 1990;82(Suppl 4):302-5.

4. Blakeman BM, Pifarré R, Sullivan H, Costanzo-Nordin MR, Zucker MJ. High-risk heart surgery in the heart transplant candidate. J Heart Lung Transplant 1990;9:468-72.

5. Louie HW, Laks H, Milgalter E, Drinkwater DC, Hamilton MA, Brunken RC, et al. Ischemic cardiomyopathy: criteria for coronary revascularization and cardiac transplantation. Circulation 1991;84(Suppl):III-290-5.

6. Luciani GB, Faggian G, Razzolini R, Livi U, Bortolotti U, Mazzucco A. Severe ischemic left ventricular failure: coronary operation or heart transplantation. Ann Thorac Surg 1993;55:719-23.

7. Rahimtoola SH. The hibernating myocardium. Am Heart J 1989;117:211-7.

8. Cigarroa CG, De Filippi CR, Brickner ME, Alvarez LG, Wait MA, Grayburn PA. Dobutamine stress echocardiography identifies hibernating myocardium and predicts recovery of left ventricular function after coronary revascularization. Circulation 1993;88:430-6.

9. Bonow RO, Dilsiziam V, Cuocolo A, Bacharach SL. Identification of viable myocardium in patients with chronic coronary artery disease and left ventricular dysfunction. Comparison of thallium scintigraphy with rejection and PET imaging with 18F-fluorodeoxyglucose. Circulation 1991;83:2637.

10. Kaul TK, Agnihotri AK, Fields BL, Riggins LS, Wyatt DA, Jones $\mathrm{CR}$. Coronary artery bypass grafting in patients with an ejection fraction of twenty or less. J Thorac Cardiovasc Surg 1996;111:1001-12.

11. Dreyfus GD, Duboc D, Blasco A, Vigoni F, Dubois C, Brodaty D, et al. Myocardial viability assessment in ischemic cardiomyopathy: benefits of coronary revascularization. Ann Thorac Surg 1994;57:1402-8.

12. Chan RKM, Raman J, Lee KJ, Rosalion A, Hicks RJ, Pornvilawan S, et al. Prediction of outcome after revascularization in patients with poor left ventricular function. Ann Thorac Surg 1996;61:1428-34.
13. Trachiotis GD, Weintraub WS, Johnston TS, Jones EL, Guyton RA, Craver JM. Coronary artery bypass grafting in patients with advanced left ventricular dysfunction. Ann Thorac Surg 1998;66:1632-9.

14. The SOLVD Investigators. Effect of enalapril on survival in patients with reduced left ventricular ejection fraction and congestive failure. N Engl J Med 1991;325:293-302.

15. Buckberg GD. Strategies and logic of cardioplegic delivery to prevent, avoid, and reverse ischemic and reperfusion damage. J Thorac Cardiovasc Surg 1987;93:127-39.

16. Baker DW, Jones R, Hodges J, Massie BM, Konstam MA, Rose EA. Management of heart failure. III. The role of myocardial revascularization in the treatment of patients with moderate or severe left ventricular systolic dysfunction. JAMA 1994;272: 1528-34.

17. Christakis ST, Weisel RD, Fremes SE, Ivanov J, David T, Goldman BS, et al. Coronary artery bypass grafting in patients with poor left ventricular function. J Thorac Cardiovasc Surg 1992;103:1083-92.

18. Langenburg SE, Buchanan SA, Blackbourne LH, Scheri RP, Sinclair KN, Martinez J, et al. Predicting survival after coronary revascularization for ischemic cardiomyopathy. Ann Thorac Surg 1995;60:1193-7.

19. Kron IL. Protection in the failing heart. Ann Thorac Surg 1999;68:1971-3.

20. Yau TM, Fedak PW, Weisel RD, Teng C, Ivanov J. Predictors of operative risk for coronary bypass operations in patients with left ventricular dysfunction. J Thorac Cardiovasc Surg 1999;118: 1006-13.

21. Di Carli MF, Maddahi J, Rokhsar S, Schelbert HR, BiancoBatlles D, Brunken RC, et al. Long-term survival of patients with coronary artery disease and left ventricular dysfunction: implications for the role of myocardial viability assessment in management decisions. J Thorac Cardiovasc Surg 1998;116:997-1004.

22. Jones E, Weintraub WS. The importance of completeness of revascularization during long-term follow-up after coronary artery operations. J Thorac Cardiovasc Surg 1996;62:401-9.

23. Elefteriades JA, Tolis G, Levi E, Mills LK, Zaret BL. Coronary artery bypass grafting in severe left ventricular dysfunction: excellent survival with improved ejection fraction and functional status. J Am Coll Cardiol 1993;22:1411-7.

24. Townend JN, Pagano D, Allen SM, Jordan P, Davies MK, Littler WA, et al. Results of surgical revascularization in ischemic heart failure without angina. Eur J Cardiothorac Surg 1995;9:507-13.

25. Pagano D, Townend JN, Littler WA, Horton R, Camici PG, Bonser RS. Coronary artery bypass surgery as treatment for ischemic heart failure: the predictive value of viability assessment with quantitative positron emission tomography for symptomatic and functional outcome. J Thorac Cardiovasc Surg 1998;115:791-9.

26. Bax JJ, Poldermans D, Elhendy A, Cornel JH, Boersma E, Rambaldi R, et al. Improvement of left ventricular ejection fraction, heart failure symptoms and prognosis after revascularization in patients with chronic coronary artery disease and viable myocardium detected by dobutamine stress echocardiography. $\mathbf{J}$ Am Coll Cardiol 1999;34:163-9.

27. Marwick TH, Zuchowski C, Lauer MS, Secknus MA, Williams J, Lytle BW. Functional status and quality of life in patients with heart failure undergoing coronary bypass surgery after assessment of myocardial viability. J Am Coll Cardiol 1999;33:750-8. 
28. Sergeant P, Blackstone E, Meyns B, Stockman B, Jashari R. First cardiological or cardiosurgical reintervention for ischemic heart disease after primary coronary artery bypass grafting. Eur $\mathbf{J}$ Cardiothorac Surg 1998;14:480-7.

29. Kron IL, Cope JT, Baker LD Jr, Spotnitz HM. The risks of reoperative coronary artery bypass in chronic ischemic cardiomyopathy: results of the CABG Patch Trial. Circulation 1997;96(Suppl 9):II-21-5.

30. Yamaguchi A, Ino T, Adachi H, Murata S, Kamio H, Okada M, et al. Left ventricular volume predicts postoperative course in patients with ischemic cardiomyopathy. Ann Thorac Surg 1997;65:434-8.
31. Loop FD, Lytle BW, Cosgrove DM, Stewart RW, Goormastic M, Williams GW, et al. Influence of the internal-mammary-artery graft on 10-year survival and other cardiac events. N Engl J Med 1986;314:1-6.

32. Sternik L, Moshkovitz Y, Hod H, Mohr R. Comparison of myocardial revascularization without cardiopulmonary bypass to standard open-heart technique in patients with left ventricular dysfunction. Eur J Cardiothorac Surg 1997;11:123-8.

33. Goldman L, Hashimoto B, Cook EF, Loscalzo A. Comparative reproducibility and validity of systems foe assessing cardiovascular functional class: advantages of a new specific activity scale. Circulation 1981;64:1227-34.

Access to The Journal of Thoracic and Cardiovascular Surgery Online is now reserved for print subscribers!

Full-text access to The Journal of Thoracic and Cardiovascular Surgery Online is now available for all print subscribers. To activate your individual online subscription, please visit The Journal of Thoracic and Cardiovascular Surgery Online, point your browser to http://www.mosby.com/jtcvs, follow the prompts to activate your online access, and follow the instructions. To activate your account, you will need your subscriber account number, which you can find on your mailing label (note: the number of digits in your subscriber account number varies from 6 to 10). See the example below in which the subscriber account number has been circled:

\section{Sample mailing label}

\begin{tabular}{|c|c|}
\hline \multirow{5}{*}{$\begin{array}{l}\text { This is your subscription } \\
\text { account number }\end{array}$} & $* * * * * * * * * * * * * * * * * * * * * * * * * * 3$-DIGIT 001 \\
\hline & 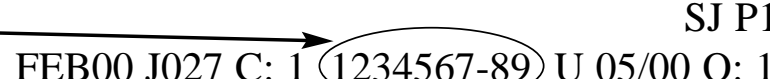 \\
\hline & J. H. DOE, MD \\
\hline & 531 MAIN ST \\
\hline & CENTER CITY, NY 10001-001 \\
\hline
\end{tabular}

Personal subscriptions to The Journal of Thoracic and Cardiovascular Surgery Online are for individual use only and may not be transferred. Use of The Journal of Thoracic and Cardiovascular Surgery Online is subject to agreement to the terms and conditions as indicated online. 